\title{
Variaciones sanguíneas y corporales en bucerros nacidos en establecimientos ganaderos de Chaco y Corrientes, Argentina
}

\author{
Koza, G.A. ${ }^{1}$; Mussart, N.B. ${ }^{1}$; Konrad, J.L. ${ }^{2}$; Hernando, J. ${ }^{1}$ Coppo, J.A. ${ }^{1}$ \\ Cátedras de Fisiología y Teriogenología ${ }^{2}$, Facultad de Ciencias Veterinarias, Universidad Nacional del Nordeste, \\ Sargento Cabral 2139, Corrientes (3400), Argentina. Tel/Fax: 03783-425753 (int 153). \\ E-mail: fisiologia@vet.unne.edu.ar
}

\begin{abstract}
Resumen
Koza, G.A.; Mussart, N.B.; Konrad, J.L.; Hernando, J.; Coppo, J.A.: Variaciones sanguíneas y corporales en bucerros nacidos en establecimientos ganaderos de Chaco y Corrientes, Argentina. Rev. vet. 25: 1, 27-33, 2014. La explotación de búfalos es una actividad en constante desarrollo en Argentina. El objetivo del ensayo fue determinar intervalos hemáticos de referencia en ejemplares juveniles (edad: 8-12 meses) criados en distintas zonas del nordeste del país. En enero de 2013 se evaluaron 30 machos de raza Mediterránea pertenecientes a dos establecimientos situados en los departamentos de Itatí $(\mathrm{E} 1, \mathrm{n}=10)$ y Empedrado $(E 2, n=10)$ en la Provincia de Corrientes y uno en San Fernando (E3, n=10), en la Provincia de Chaco, todos en buen estado de salud. Se registró el peso vivo (PV) y el perímetro torácico (PT), realizándose análisis hematológicos y bioquímicos. Los datos se procesaron bajo un diseño en bloques completos al azar, efectuándose estadísticas descriptivas y análisis de la varianza a una vía $(\mathrm{p}<0,05)$. PV resultó más elevado en E1 y E2 con relación a E3. PT fue superior en E1. Eritrocitos, hematocrito y hemoglobina fueron más altos en E1 y E2. Los leucocitos resultaron más elevados en E1 y E3. Proteínas totales, albúminas, colesterol, triglicéridos, C-HDL y C-LDL revelaron niveles más altos en E3, en tanto que E1 registró los mayores niveles de urea, calcio, magnesio y glucosa. En cambio, fructosamina no reveló diferencias significativas entre grupos. Las actividades más altas de las enzimas ALP, GGT y AST se constataron en E3, pero LDH fue mayor en E1. Las diferencias deberían atribuirse a la zona geográfica (clima, pasturas) y quizás a los sistemas de manejo de cada establecimiento. Se espera que los intervalos de referencia aquí obtenidos asuman utilidad para el diagnóstico de enfermedades y la valoración del estado nutricional de machos bubalinos en estadio juvenil de la raza Mediterránea en el nordeste argentino.
\end{abstract}

Palabras clave: búfalo, joven edad, parámetros corporales, variaciones hemáticas, Argentina.

\begin{abstract}
Koza, G.A.; Mussart, N.B.; Konrad, J.L.; Hernando, J.; Coppo, J.A.: Hematic and corporal variations in juvenile buffalos born in farms from Chaco and Corrientes, Argentina. Rev. vet. 25: 1, 27-33, 2014. The breeding of buffalos is an activity in constant development in Argentina. The objective of this assay was to determine blood reference intervals in juvenile buffalos (age: 8-12 months) maintained in different areas of the northeast region of Argentina. In January 2013, thirty healthy male Mediterranean buffalos from two farms located in the departments of Itati $(E 1, n=10)$ and Empedrado $(E 2, n=10)$ from Corrientes Province and one in San Fernando (E3, n=10 from Chaco Province, were evaluated. Liveweight (PV) and thoracic perimeter (PT), as well as different hematological and biochemical parameters, were registered. Data were processed by a complete randomized block design using descriptive statistics and one-way analysis of variance $(\mathrm{p}<0.05)$. PV was higher in E1 and E2 compared to E3. PT was higher in E1. Red blood cells, packed cell volume and hemoglobin concentration were higher in E1 and E2. Total leukocytes were higher in E1 and E3. Total protein, albumin, cholesterol, triglycerides, HDL-C and LDL-C revealed higher levels in E3, whereas E1 registered the highest urea, calcium, magnesium and glucose levels. On the other hand, fructosamine did not reveal significant differences among groups. The highest enzymatic activities of ALP, GGT and AST were verified in E3, but LDH was increased in E1. Such differences should be attributed to the geographical area conditions (climate, pastures) and perhaps to the handling systems of each farm. The reference intervals obtained in this work
\end{abstract}


may be useful for the diagnosis of diseases and the evaluation of the nutritional state from Mediterranean juvenile male buffalos from Northeastern Argentina.

Key words: buffalo, young stage, body parameters, blood variations, Argentina.

\section{INTRODUCCIÓN}

La explotación de búfalos es una actividad en constante desarrollo en el nordeste argentino. En el año 2006 existía la siguiente distribución de ganado bubalino en el país: Corrientes: $45 \%$, Formosa: $45 \%$, Chaco: 5,6\%, Entre Ríos: 2,2\%, Misiones: $1,1 \%$ y otras provincias (incluyendo Buenos Aires, Tucumán, Salta, Santa Fe, La Pampa y Mendoza): $1,1 \%{ }^{18}$. Se estima que actualmente la existencia de búfalos asciende 100.000 cabezas, distribuidas principalmente en las provincias de Formosa, Corrientes y Chaco.

Los búfalos de agua (Bubalus bubalis) son animales de gran rusticidad, la cual asociada a su capacidad de adaptación a las adversidades del medio, precocidad, longevidad, larga vida útil productiva y reproductiva (de 15 a 20 años), elevada tasa de natalidad (superior al $80 \%$ ), baja tasa de mortalidad (inferior al 3\% anual) y temperamento dócil, los califican como una excelente alternativa productiva, sobre todo para aquellas regiones donde las condiciones geográficas y climáticas no son las óptimas para la explotación del ganado vacuno ${ }^{16}$.

En algunas regiones y bajo ciertas circunstancias, los búfalos ostentan una serie de atributos fisiológicos inherentes a la especie, que hacen que su explotación, sea más ventajosa que la de los bovinos ${ }^{27}$. Los bubalinos son los animales productivos más ahorrativos, versátiles y adaptables, que en las últimas décadas han captado la atención de las empresas ganaderas dedicadas a la obtención de carne y leche para consumo humano.

Una marcada limitación del ganado bubalino es su susceptibilidad al estrés térmico ${ }^{1}$ debido a la escasez de eficientes mecanismos de enfriamiento por evaporación cutánea ${ }^{5}$. Las temperaturas elevadas conducen a una disminución en el consumo de alimentos, afectando de esta manera la regulación del calor. Los parámetros hematológicos operan como eficientes indicadores del estrés calórico ${ }^{17}$. Sin embargo, varios factores como raza, especie, edad, sexo, hora del día y estado fisiológico deben ser considerados, ya que ellos pueden modificar los valores de referencia, alterando su interpretación ${ }^{11}$.

La malnutrición es otro factor restrictivo para el desarrollo del búfalo ${ }^{3}$. Las deficiencias alimentarias, combinadas con la reducción del consumo voluntario, desencadenan pérdida de peso y disminución de la condición corporal, generando importantes limitaciones en la producción y reproducción la especie bubalina ${ }^{12}$.

La obtención de intervalos de referencia regionales para valores de laboratorio asume importancia al mo- mento de optimizar el diagnóstico de enfermedades del búfalo, como así también la valoración de indicadores nutricionales sanguíneos, que conjuntamente con la medición de parámetros pondo-estaturales, constituyen herramientas útiles para mejorar la eficacia de los emprendimientos productivos.

El objetivo del presente trabajo fue investigar los intervalos de referencia de algunos parámetros corporales y hemáticos de bucerros nacidos en dos establecimientos ganaderos de la Provincia de Corrientes (Itatí y Empedrado) y uno de la Provincia de Chaco (San Fernando).

\section{MATERIAL Y MÉTODOS}

Los sujetos experimentales fueron 30 búfalos de raza Mediterránea, sexo macho, de la categoría bucerros no lactantes, de 8 a 12 meses de edad, divididos en tres grupos de 10 animales cada uno, según su lugar de origen. Los ejemplares fueron seleccionados al azar a partir de los rodeos generales de dos establecimientos ganaderos situados en los departamentos de Itatí (E1) y Empedrado (E2), Provincia de Corrientes y otro ubicado en San Fernando, Provincia de Chaco (E3), en todos los casos con alimentación a campo natural y similar manejo sanitario. La experiencia se realizó en enero de 2013.

Se procedió al registro del peso vivo PV (en báscula), medición del perímetro torácico PT (cinta métrica), así como a la extracción de sangre por veno-punción yugular. La sangre se fraccionó en dos alícuotas, una con anticoagulante (EDTA) y otra sin anticoagulante, para la obtención de suero.

Con la sangre entera se efectuaron valoraciones de hematocrito, hemoglobina, recuento de glóbulos rojos y blancos, estimación de índices hematimétricos (VCM: volumen corpuscular medio, HCM: hemoglobina corpuscular media y CHCM: concentración de hemoglobina corpuscular media), así como fórmula leucocitaria absoluta, de acuerdo a técnicas convencionales ${ }^{6,11}$.

Con el suero obtenido, se procedió a la determinación de proteínas totales (método del Biuret) y fracciones seroproteicas (albúmina y globulinas alfa, beta y gamma) por electroforesis en soporte de acetato de celulosa, buffer de veronal sódico y coloración amidoschwartz, con ulterior transparentización y cuantificación por densitometría. La relación albúmina/globulina se obtuvo por cálculo. También se valoraron: triglicéridos (técnica lipasa peroxidasa), colesterol total (oxidasa peroxidasa), colesterol ligado a lipoproteínas de alta y baja densidad (C-HDL y C-LDL por precipitación selectiva de lipoproteínas), glucosa (oxidasa peroxidasa), 
fructosamina (nitrotetrazolio), calcio (arsenazo), fósforo inorgánico (molibdato ascorbato), magnesio (xylidyl blue), gammaglutamil transpeptidasa GGT (cinética c/p-nitroanilida), aspartato aminotransferasa AST (método UV c/NADH/L-aspartato), fosfatasa alcalina ALP (técnica del fenilfosfato aminoantipirina) y lactato deshidrogenasa LDH (técnica del NADlactato) ${ }^{6,11}$.

La estadística descriptiva, el análisis de la varianza y la diferencia entre medias (test de Tukey), se efectuaron en el marco de un diseño en bloques completos al azar (bloqueo por departamento donde radicaba el establecimiento ganadero), con la ayuda del programa estadístico InfoStat Profesional, versión 1.1 (2008).

\section{RESULTADOS Y DISCUSIÓN}

El PV fue más elevado en los bucerros de los establecimientos situados en la Provincia de Corrientes (E1: $342,38 \pm 41,70 \mathrm{~kg}$ y E2: $324,10 \pm 32,41 \mathrm{~kg}$ ), con relación a los evaluados en la Provincia del Chaco (E3: $198,85 \pm 20,36 \mathrm{~kg}), \mathrm{p}=0,0001$. El valor medio de PV para el total de los bucerros fue de $297,5 \pm 66,57 \mathrm{~kg}$. Tales guarismos no discrepan de los habituales para esta raza, en la cual el peso al nacimiento sería de unos 70 $\mathrm{kg}$ y al momento del destete ( 7 meses de edad, aproximadamente) se habría elevado hasta $220-260 \mathrm{~kg}$. Se estima que la ganancia diaria de peso es ininterrumpida desde el nacimiento hasta los 15 meses. A la edad de 30 meses, con pesos de alrededor de $550 \mathrm{~kg}$, los búfalos se destinan a la faena ${ }^{18}$.

El PT se presentó significativamente más alto en los bucerros de Itatí $(166,13 \pm 8,10 \mathrm{~cm})$, en comparación con los de Empedrado $(161,40 \pm 8,10 \mathrm{~cm})$ y San Fernando $(154,43 \pm 7,68 \mathrm{~cm}), \mathrm{p}=0,032$. El PT medio fue de $160,96 \pm 8,94 \mathrm{~cm}$. Las diferencias de PT y PV entre bucerros de distintas localidades se explicaría por las distintas edades (Chaco: 8 meses, Corrientes: 11 meses en promedio) y las disímiles condiciones medioambientales de recría, porque los parámetros pondoestaturales variarán según el contenido energético-proteico de la ración. Se ha reportado que el búfalo es más eficiente que el bovino en la utilización de alimentos fibrosos de baja calidad y que el nivel de energía afecta significativamente la ganancia de peso vivo y desarrollo corporal de los bucerros ${ }^{15}$.

En la Tabla 1 se reseña el comportamiento de los parámetros del hemograma. Los valores de hematocrito, eritrocitos, hemoglobina, VCM y CHCM resultaron ser significativamente más elevados en E2. HCM no reveló diferencias significativas entre los bucerros de las distintas localidades. Los valores de hematocrito aquí obtenidos son más altos que los hallados por otros investigadores (33 a 35\%) para búfalos menores de un año ${ }^{14}$. En búfalos de distintas razas y sus cruzas, menores de 270 días, de ambos sexos, mantenidos a campo natural en la región occidental de Venezuela, se encontraron valores de $35 \%$ de hematocrito, 7,43 T/1 de eritrocitos, 12,11 g/dl de hemoglobina, VCM de $51 \mathrm{fl}$, HCM de 17 pg y CHCM de $35 \%{ }^{19}$. Para bucerros lactantes se publicaron valores de 7,79 T/1 para hematíes, $37 \%$ para hematocrito y $11,96 \mathrm{~g} / \mathrm{dl}$ para hemoglobina ${ }^{20}$.

En búfalos de 6 a 11 meses de edad se registraron tasas de hematocrito (38\%), hemoglobina $(12,95 \mathrm{~g} / \mathrm{dl})$ y glóbulos rojos $(8,57 \mathrm{~T} / \mathrm{l})$ que resultan sensiblemente menores a los obtenidos en la presente experiencia $(41 \%, 15,09 \mathrm{~g} / \mathrm{dl} \text { y } 9,14 \mathrm{~T} / \mathrm{l})^{8}$.

$\mathrm{Al}$ analizar las variables hematológicas de búfalos de Venezuela, de hasta 30 meses de edad, no se encontraron diferencias significativas entre sexos salvo en los valores de hematocrito, que fue mayor en hembras (37\%) que en machos (35\%). En la misma investigación, dividiendo a los animales según sus pesos (hasta 150 $\mathrm{kg}$, de 150-350 kg y mayores de $350 \mathrm{~kg}$ ), surgió que las diferencias se acentuaban entre los animales del primer y segundo grupo con respecto al tercero, revelando descensos de eritrocitos y hematocrito, así como aumentos de hemoglobina, HCM y CHCM, permaneciendo sin variación el VCM. En el grupo de $150-350 \mathrm{~kg}$ se situarían los sujetos experimentales de la presente experiencia $(297 \mathrm{~kg})$, que mostraron sus variables hematológicas sensiblemente superiores a las mencionadas ${ }^{19}$.

En Brasil, bucerras de 9 a 12 meses de edad, de las razas Jafarabadi, Murrah y Mediterránea, registraron valores de eritrocitos $(9,13 \mathrm{~T} / \mathrm{l})$, hemoglobina $(14,10 \mathrm{~g} /$ $\mathrm{dl})$, hematocrito (43\%), VCM (48 fl), HCM (17 pg) y CHCM (33\%) semejantes a los aquí encontrados, aunque se hallaron diferencias entre razas ${ }^{22}$.

Los parámetros hematológicos se utilizan como indicadores de estrés calórico en el ganado ${ }^{17}$. Para comprobar los efectos del estrés térmico en búfalos dotados o no de sombra, se halló que en los periodos del

Tabla 1. Variables hemáticas según procedencia de los bucerros.

\begin{tabular}{lccccc}
\hline variable & $\overline{\mathrm{x}} \pm \mathrm{DE}$ & $\mathrm{E} 1$ & $\mathrm{E} 2$ & $\mathrm{E} 3$ & $\mathrm{p}$ \\
\hline hematocrito (\%) & $41 \pm 3,87$ & $40 \mathrm{a}$ & $45 \mathrm{~b}$ & $38 \mathrm{a}$ & $0,0001^{*}$ \\
eritrocitos (T/l) & $9,14 \pm 0,8$ & $9,23 \mathrm{a}$ & $9,69 \mathrm{a}$ & $8,24 \mathrm{~b}$ & $0,0001^{*}$ \\
hemoglobina (g/dl) & $15,09 \pm 1,20$ & $15,43 \mathrm{a}$ & $15,6 \mathrm{a}$ & $13,98 \mathrm{~b}$ & $0,009^{*}$ \\
VCM (fl) & $45 \pm 1,46$ & $44 \mathrm{a}$ & $46 \mathrm{~b}$ & $46 \mathrm{~b}$ & $0,0006^{*}$ \\
$\mathrm{HCM}(\mathrm{pg})$ & $17 \pm 0,9$ & 17 & 16 & 17 & 0,106 \\
CHCM (\%) & $37 \pm 2,17$ & $38 \mathrm{a}$ & $35 \mathrm{~b}$ & $37 \mathrm{a}$ & $0,002^{*}$ \\
leucocitos (G/l) & $14,54 \pm 4,56$ & $17,58 \mathrm{a}$ & $10,5 \mathrm{~b}$ & $16,83 \mathrm{a}$ & $0,0002^{*}$ \\
neutrófilos (G/1) & $4,69 \pm 1,87$ & $5,14 \mathrm{ab}$ & $3,36 \mathrm{a}$ & $6,06 \mathrm{~b}$ & $0,005^{*}$ \\
linfocitos (G/l) & $8,53 \pm 2,61$ & $10,22 \mathrm{a}$ & $6,42 \mathrm{~b}$ & $9,62 \mathrm{a}$ & $0,001^{*}$ \\
monocitos (G/1) & $0,49 \pm 0,29$ & 0,63 & 0,40 & 0,48 & 0,271 \\
eosinófilos (G/1) & $0,81 \pm 1,02$ & $1,56 \mathrm{a}$ & $0,31 \mathrm{~b}$ & $0,67 \mathrm{ab}$ & $0,03^{*}$ \\
basófilos (G/l) & $0,01 \pm 0,05$ & 0,03 & 0,01 & 0 & 0,59 \\
\hline
\end{tabular}

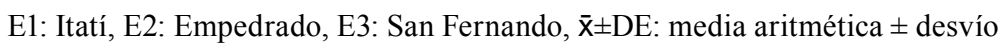
estándar, p: significación $\left({ }^{*} \mathrm{p}<0,05\right)$. VCM: volumen corpuscular medio, HCM: hemoglobina corpuscular media, CHCM: concentración de HCM. En cada línea letras iguales expresan diferencias no significativas (Tukey test). 
año con menos lluvias, el grupo de animales sin sombra reveló mayores concentraciones de eritrocitos. Los niveles de hemoglobina fueron mayores durante los períodos de transición y los menos lluviosos, revelando correlación negativa $(p<0,05)$ con la temperatura y la humedad relativa ${ }^{24}$.

En la presente investigación, glóbulos blancos totales, linfocitos y eosinófilos fueron más elevados en los animales de los establecimientos E1 y E3, con relación a E2. La concentración de neutrófilos se presentó significativamente más alta en los bucerros de Chaco, con relación a los oriundos de Corrientes (Tabla 1).

Un estudio sobre el leucograma de búfalos indicó que no existieron diferencias atribuibles a las razas (Mediterránea, Jaffarabadi y Murrah), pero sí a la edad, ya que al incrementarse provocaba la elevación de neutrófilos y eosinófilos, con disminución de los leucocitos totales y linfocitos. Para bucerras de 9 a 12 meses se reportaron valores de $15,23 \mathrm{G} / 1$ para glóbulos blancos, $3,87 \mathrm{G} / 1$ de neutrófilos $10,58 \mathrm{G} / 1$ de linfocitos, $0,17 \mathrm{G} / 1$ de monocitos, $0,45 \mathrm{G} / 1$ de eosinófilos y $0,16 \mathrm{G} / 1$ de basófilos ${ }^{23}$.

Al evaluar búfalos de 12 y 24 meses de edad se obtuvieron valores de glóbulos blancos de 11,9 G/1 para el grupo más joven y de 14,1 G/1 para los más viejos ${ }^{9}$. Búfalos de Colombia revelaron recuentos diferenciales con $22-26 \%$ de neutrófilos, $66-69 \%$ de linfocitos, $4-6 \%$ de monocitos, $1-2 \%$ de eosinófilos y $0,2-0,5 \%$ de basófilos ${ }^{14}$. En nuestra experiencia las tasas de neutrófilos y eosinófilos fueron más altas $(31,92$ y 4,96\%) y las de linfocitos, monocitos y basófilos fueron más bajas $(59,64 ; 3,40$ y $0,08 \%)$. Otros autores ${ }^{8}$ citan valores de recuentos diferenciales muy similares a los aquí hallados (neutrófilos 30,92\%, linfocitos $65 \%$, monocitos $3,23 \%$ y eosinófilos $0,92 \%$ ), no así para el recuento de leucocitos totales, que resultó menor $(10,24 \mathrm{G} / \mathrm{l})$ al encontrado en nuestro trabajo $(14,54 \mathrm{G} / 1$, valor promedio de los tres establecimientos).

En búfalos brasileros de un año de edad, parasitados con nematodos gastrointestinales, se constataron reducciones significativas de hemoglobina y hematocrito, así como marcados aumentos de leucocitos y eosinófilos. La intensidad de estos cambios varió según la cantidad y especie de parásitos presentes en el tubo gastrointestinal. Los investigadores comprobaron que las parasitosis pueden reducir la capacidad de desarrollo y producción de los búfalos. La severidad de estos cambios y el tipo de respuesta inmune, serían proporcionales a la edad del animal, especie y cantidad de parásitos, ubicación del establecimiento ganadero, época del año, prácticas nutricionales, maniobras de control parasitario y tipo de sistema de producción ${ }^{3}$.

En el estrés térmico en búfalas se observó que durante la temporada de lluvias, el grupo de animales provistos de sombra, mostró mayores niveles de leucocitos, mientras que durante los períodos de transición y menos lluvia, dichos niveles fueron mayores en el grupo al que no se le brindó reparo del sol ${ }^{24}$.

En la Tabla 2 se consignan los resultados del proteinograma sérico. Las proteínas totales, albúmina, alfa globulinas y relación albúmina-globulinas se presentaron significativamente más elevadas en los bucerros de Chaco. Las beta globulinas fueron más elevadas en E2 que en E1 y E3, mientras que las gamma globulinas presentaron mayores niveles en E1. Las globulinas totales no mostraron diferencias atribuibles al establecimiento de origen de los búfalos explorados.

En experiencias realizadas en Filipinas sobre búfalos jóvenes, se reportó un valor promedio de proteínas totales de 5,86 g/d ${ }^{10}$. En ganado bubalino de Colombia se puso en evidencia una tendencia ascendente de las proteínas séricas al avanzar la edad. Así, bucerros menores de un año registraron proteínas totales de 8,1-8,2 $\mathrm{g} / \mathrm{dl}$, animales de 1 a 3 años revelaron poseer 8,4-8,5 $\mathrm{g} / \mathrm{dl}$ y búfalos mayores a 3 años ostentaron tenores de $8,8-8,9 \mathrm{~g} / \mathrm{dl}^{14}$.

En Zuliá (Venezuela) se realizaron estudios epidemiológicos en búfalos de agua y de pantanos, determinándose anticuerpos contra diferentes agentes patógenos. Las determinaciones de inmunoglobulinas en adultos y jóvenes (IgM, IgG e IgA) variaron significativamente por la edad, sexo y sistema de amamantamiento ${ }^{25,26}$. 
Tabla 4. Metabolitos y minerales séricos según procedencia de los bucerros.

\begin{tabular}{lccccc}
\hline variable & $\overline{\mathrm{x}} \pm \mathrm{DE}$ & $\mathrm{E} 1$ & $\mathrm{E} 2$ & $\mathrm{E} 3$ & $\mathrm{p}$ \\
\hline urea $(\mathrm{g} / \mathrm{l})$ & $0,37 \pm 0,10$ & $0,43 \mathrm{a}$ & $0,42 \mathrm{a}$ & $0,23 \mathrm{~b}$ & $0,0001^{*}$ \\
glucosa $(\mathrm{g} / \mathrm{l})$ & $0,77 \pm 0,17$ & $0,88 \mathrm{a}$ & $0,76 \mathrm{~b}$ & $0,66 \mathrm{~b}$ & $0,04^{*}$ \\
fructosamina $(\mu \mathrm{mol} / \mathrm{l})$ & $262 \pm 90$ & 284 & 233 & 276 & 0,454 \\
calcio $(\mathrm{mg} / \mathrm{dl})$ & $10,03 \pm 0,77$ & $10,73 \mathrm{a}$ & $9,46 \mathrm{~b}$ & $10,06 \mathrm{ab}$ & $0,0004^{*}$ \\
fósforo inorg. $(\mathrm{mg} / \mathrm{dl})$ & $6,89 \pm 1,06$ & 6,53 & 6,70 & 7,58 & 0,119 \\
magnesio $(\mathrm{mg} / \mathrm{dl})$ & $3,19 \pm 0,31$ & $3,54 \mathrm{a}$ & $3,17 \mathrm{~b}$ & $2,84 \mathrm{c}$ & $0,0001^{*}$ \\
\hline
\end{tabular}

E1: Itatí, E2: Empedrado, E3: San Fernando, $\bar{x} \pm$ DE: media aritmética \pm desvío estándar, $p$ : significación $\left({ }^{*} p<0,05\right)$. En cada línea letras iguales expresan diferencias no significativas (Tukey test).

Tabla 5. Actividades enzimáticas en suero de bucerros, según procedencia.

\begin{tabular}{lccccc}
\hline variable & $\overline{\mathrm{x}} \pm \mathrm{DE}$ & $\mathrm{E} 1$ & $\mathrm{E} 2$ & $\mathrm{E} 3$ & $\mathrm{p}$ \\
\hline fosfatasa alcalina $(\mathrm{U} / \mathrm{l})$ & $263 \pm 96$ & $231 \mathrm{a}$ & $246 \mathrm{a}$ & $326 \mathrm{~b}$ & $0,014^{*}$ \\
gamma glutamiltransferasa (U/1) & $9 \pm 4$ & $10 \mathrm{a}$ & $6 \mathrm{~b}$ & $13 \mathrm{c}$ & $0,0001^{*}$ \\
aspartato aminotransferasa (U/1) & $43 \pm 19$ & $8 \mathrm{a}$ & $37 \mathrm{~b}$ & $62 \mathrm{c}$ & $0,002^{*}$ \\
lactato deshidrogenasa (U/1) & $293 \pm 82$ & $373 \mathrm{a}$ & $228 \mathrm{~b}$ & $297 \mathrm{c}$ & $0,0001^{*}$ \\
\hline
\end{tabular}

E1: Itatí, E2: Empedrado, E3: San Fernando, $\overline{\mathrm{x}} \pm \mathrm{DE}$ : media aritmética \pm desvío estándar, $\mathrm{p}$ : significación $(* \mathrm{p}<0,05)$. En cada línea letras distintas expresan diferencias significativas (Tukey test).

En Paraná (Brasil) se evaluó el efecto antihelmíntico y los cambios metabólicos producidos por la administración de torta de maíz con el agregado de aceite de neem y ajo deshidratado, en búfalas lecheras de 3 a 10 años de edad. El análisis coprológico mostró un marcado descenso de los huevos de parásitos, pero también disminuyeron hematocrito (34 a $29 \%$ ) y proteinemia total $(7,77$ a $6,56 \mathrm{~g} / \mathrm{dl})$, por lo cual los investigadores concluyeron que la experiencia generó inhibición de la oviposición, sin erradicar la parasitosis gastrointestinal ${ }^{13}$.

En la Tabla 3 se indican los valores obtenidos para los lípidos séricos. Todas las variables analizadas resultaron más altas en los animales provenientes de Chaco. Los niveles séricos de los parámetros lipídicos estudiados no mostraron concordancia con los obtenidos para bubillas Murrah suplementadas con alimentos de alto tenor energético, quienes exhibieron mayores concentraciones séricas de glucosa, colesterol total y C-HDL, en relación a aquéllas que consumieron raciones de bajo contenido calórico ${ }^{4}$. En nuestra experiencia, los animales de Chaco revelaron un regular estado general, mientras que los de Corrientes ostentaron estados corporales de bueno a muy bueno, debido principalmente a la mejor calidad y disponibilidad forrajera de los campos naturales de dicha zona.

En experiencias donde se evaluaron los efectos de la restricción alimentaria, se observaron marcados incrementos de los triglicéridos sanguíneos, como consecuencia probable de la mayor lipólisis del tejido graso de reserva ${ }^{21}$. El nivel sérico de colesterol estaría en estrecha relación con el contenido de grasas de la ración ${ }^{6}$. Los niveles de colesterol total $(0,66 \mathrm{~g} / \mathrm{l})$ y triglicéridos $(0,33 \mathrm{~g} / \mathrm{l})$ revelaron aumentos significativos $(0,71$ y 0,54 $\mathrm{g} / \mathrm{l}$ respectivamente) al suplementar búfalos mediante torta de maíz con el agregado de aceite de neem y ajo deshidratado (como antihelmíntico) ${ }^{13}$.

En la Tabla 4, se consignan los resultados obtenidos para algunos metabolitos y electrolitos séricos. Los mayores niveles de urea y glucosa ocurrieron en los establecimientos correntinos. El valor medio obtenido para la urea sérica $(0,37 \pm 0,10 \mathrm{~g} / \mathrm{l})$ enmarcó dentro del rango fisiológico citado para bovinos $^{6,11}$. La uremia constituye un eficiente parámetro indicador del metabolismo nitrogenado del rumiante, pues revela los movimientos de este compuesto y sus derivados, a través del rumen e hígado ${ }^{7}$.

Los valores de glucosa sérica obtenidos en este trabajo $(0,77 \pm 0,17 \mathrm{~g} / \mathrm{l}$ en promedio) fueron ligeramente superiores a los citados por otros autores en bovinos $(0,40 \text { a } 0,50 \mathrm{~g} / \mathrm{l})^{6}$. La glucemia se presentaría más elevada en los terneros bovinos, descendiendo a valores de adultos hacia las 8 semanas de vida, paralelamente al incremento de la producción de ácidos grasos volátiles a nivel ruminal ${ }^{28}$.

La fructosamina no se vio afectada por la diferente ubicación de los establecimientos de origen. En la bibliografía consultada existen muy escasos datos de este indicador metabólico de los carbohidratos en rumiantes. En nuestros laboratorios habitualmente se obtienen valores de 214 a $236 \mu \mathrm{mol} / 1$ para terneros de 6 a 8 meses de edad, guarismos que no se apartan mucho de los obtenidos para bucerros $(262 \pm 90 \mu \mathrm{mol} / \mathrm{l})$.

El calcio sérico registrado en la presente experiencia (promedio: 10,03 $\pm 0,77 \mathrm{mg} / \mathrm{dl}$ ), se encuentra dentro del rango fisiológico citado para bovinos (10,4 a 11,7 $\mathrm{mg} / \mathrm{dl})^{6}$. Es conocido que las hipocalcemias no necesariamente indicarían deficiencias dietarias de calcio debido a que sus niveles sanguíneos se encuentran regulados hormonalmente. Bajo esta óptica se señala que los valores más bajos del electrolito se verificaron en Empedrado, en relación a las concentraciones registradas en Itatí y San Fernando.

Los niveles de magnesemia aquí registrados encuadran dentro del marco de referencia citado en la bibliografía para bovinos $(2,4$ a $3,3 \mathrm{mg} / \mathrm{dl})$. Los tenores de fósforo inorgánico de los búfalos fueron más elevados que los citados en la bibliografía para vacunos, 4 a 5 $\mathrm{mg} / \mathrm{dl}$. Es menester aclarar que en bovinos jóvenes, la fosfatemia puede presentarse más elevada (de 8,3 a 9,5 $\mathrm{mg} / \mathrm{dl})^{6}$.

En la Tabla 5 se muestran los valores obtenidos para algunas enzimas séricas de importancia diagnóstica. Los animales de E3 (en su mayoría de 8 meses de edad), ostentaron mayores niveles de ALP que los registrados 
por E1 y E2 (en promedio 11 meses). En bucerros menores de un año de edad, otros investigadores obtuvieron para ALP y AST actividades de $104 \pm 4,5 \mathrm{U} / 1$ y de $98,4 \pm 0,70 \mathrm{U} / 1$ respectivamente ${ }^{15}$. Los mayores niveles séricos de ALP en animales jóvenes se deberían al incremento de la isoenzima ósea, reveladora de una elevada actividad osteoblástica acorde al crecimiento óseo ${ }^{6}$.

Investigadores brasileros no registraron diferencias significativas en las actividades séricas de AST (70 vs $65 \mathrm{UI} / \mathrm{l})$, GGT (3 vs $2 \mathrm{UI} / 1$ ) y ALP (129 vs $135 \mathrm{UI} / 1)$, previa y posteriormente a la administración de torta de maíz con aceite de neem y ajo deshidratado como tratamiento antihelmíntico ensayado en búfalas lecheras de la raza Munrrah ${ }^{13}$.

En una intoxicación experimental de búfalos con Cestrum laevigatum, una planta con marcada actividad hepatotóxica, los animales revelaron niveles previos de GGT, AST y bilirrubina total de 16,33 UI/1, 148,5 UI/1 y $0,37 \mathrm{mg} / \mathrm{dl}$, respectivamente. Post intoxicación $(20 \mathrm{~g} /$ $\mathrm{kg}$ peso) los búfalos incrementaron los niveles enzimáticos $(128,3 \mathrm{UI} / 1$ y $379,16 \mathrm{UI} /)$ y de bilirrubina $(0,84$ $\mathrm{mg} / \mathrm{dl}$ ), en correlación con la aparición de sintomatología y lesiones histopatológicas. La administración de una dosis mayor $(40 \mathrm{~g} / \mathrm{kg}$ peso) resultó letal para estos animales ${ }^{2}$.

En conclusión, se aportan datos pondoestaturales (peso vivo, perímetro torácico) y valores de referencia para eritrograma, leucograma, proteinograma, lipidograma, perfil mineral, metabolitos séricos y enzimas de interés diagnóstico, obtenidos en bucerros de raza Mediterránea de tres establecimientos del nordeste argentino. Tal información, hasta ahora inexistente, se agrega al bagaje de información necesaria para optimizar el diagnóstico de enfermedades y la valoración del estado nutricional del ganado bubalino, especie de creciente expansión productiva regional.

Agradecimientos. Al Dr. Gustavo Crudeli por su colaboración en las tareas de campo y redacción del presente trabajo.

\section{REFERENCIAS}

1. Abou-Zeina HA, Hassan SG, Sabra HA, Hamam AM. 2009 Trials for elevating adverse effect of heat stress in buffaloes with emphasis on metabolic status and fertility. Glob Vet 3: 51-62.

2. Barbosa JD, Oliveira CM, Pinheiro C, Lopes CT, Marquiore D, Brito MF, Yamasaki EM, Tokarnia CH. 2010. Intoxicação por Cestrum laevigatum (Solanaceae) em bubalinos. Pesq Vet Bras 30: 1049-1052.

3. Bastianetto E, Martins M, Cerqueira R. 2011. Hemogram of buffaloes (Bubalus bubalis) wormed and nonwormed by helminthes. $R$ bras $C i$ Ve 18: 102-110.

4. Campanile G, Baruselli PS, Vecchio D, Prandi A, Neglia G, Carvalho NA, Sales JN, Gasparrini B, D'occhio JM. 2010. Growth, metabolic status and ovarian function in buffalo (Bubalus bubalis) heifers fed a low energy or high energy diet. Anim Reprod Sci 22: 74-81.
5. Cockrill WR. 1993. Developing the water buffalo: a decade of promise. Buffalo Journal 9: 1-11.

6. Coles EH. 1989. Veterinary Clinical Pathology. $4^{\text {th }}$ ed., Saunders, Philadelphia, $486 \mathrm{p}$.

7. Correa CH, Cuellar GA. 2004. Aspectos claves del ciclo de la urea con relación al metabolismo energético y proteico en vacas lactantes. Rev Col Cienc Pec 17: 29-38.

8. Ferrer JM, Árraga CM, Barboza M. 2000. Caracterización hematológica de Bubalus bubalis por sexo y edad. Revista Cientifica FCV-LUZ 10: 508-514.

9. França R, Dos Anjos S, Brolo D, Machado M, Do Rêgo M, Melazzo C, Schuh R, Lopes G. 2011. Valores hematológicos de búfalos em diferentes faixas etárias criados na região central do Rio Grande do Sul. Rev Bras Cien Vet 1:51-54.

10. Galagnara A, Cruzado A. 1999. Hematology and serum biochemistry of bulgarian Murrah buffaloes (Bubalus bubalis) at the Philippine Carabao Center. On line: http:// www.chicagomanualofstyle.org/home.html (acceso: febrero 2013).

11. Jain NC. 1993. Essentials of Veterinary Hematology, Lea \& Febiger, Philadelphia, $417 \mathrm{p}$.

12. Jainudeen MR, Hafez ES. 1993. Cattle and buffalo. In: Reproduction in Farm Animals (Hafez E.S. ed.), $6^{\text {th }}$ ed., Lea \& Febiger, Philadelphia, p 315-329.

13. Lipinski LC, Martinez JL, Santos MV, Ferreira JN, Pfau DR. 2011. Avaliação do efeito anti-helmíntico e das alterações metabólicas em búfalos (Bubalus bubalis) com administração da torta de neem e do alho desidratado no sul do Paraná. Rev Bras Agroecol 6: 168-175.

14. Londoño RC, Sánchez ME, Prada GA. 2012. Parámetros fisiológicos y valores hematológicos normales en búfalos (Bubalus bubalis) del Magdalena Medio colombiano. Rev Med Vet 23: 51-64.

15. Madan J, Puri, JP, Singh JK. 2009. Growth, feed efficiency and blood profile of buffalo calves consuming high levels of fluoride. Growth and blood metabolites in buffaloes fed. Trop Anim Health Prod 41: 295-298.

16. Moreira P, Costa AL, Valentin JF. 1994. Comportamento produtivo e reprodutivo de bubalinos mestiços Murrah-Mediterrâneo em pastagem cultivada em terra firme no Estado do Acre. Boletim de Pesquisa Emprapa-CPAF 13, p.19.

17. Paes PR, BarioniG, Fonteque JR. 2000. Comparison of hematological values among different aged female goats of the Parda Alpina breed. Veterinária Notícias (Uberlândia, Brasil) 1: 43-49.

18. Patiño EM, Crudelli GA, Mitat A, Simplicio JF, Gusmao A, Jacobo R, López OC, Sánchez Negrette M, Almirón LR, Rébak GI. 2011. Bubalinocultura de las Américas, Ed. Moglia, Corrientes, Argentina, p 11-136.

19. Ramírez LN, Azuaje KK, Sanchéz F, Díaz A. 1999. Observaciones hematológicas en búfalos de agua (Bubalus bubalis) aparentemente sanos en el occidente de Venezuela. Revista Cientifica FVC-LUZ 9: 524-531.

20. Ramírez LN, Araujo GF, Díaz A. 2007. Hematología en búfalas lecheras mestizas (Bubalus bubalis) y sus crías en un rebaño ubicado en una zona de bosque seco tropical. Mundo Pecuario 3: 90-95. 
21. Rodríguez EJ, Carande VG, Rodríguez VA. 1985. Efectos de la restricción y la realimentación sobre la concentración de metabolitos sanguíneos. Ver Arg Prod Anim 5: $1-12$.

22. Silva MB, D'Angelino JL, Araujo WP, Galhardo M, Garcia M, Birgel EH. 1992. Avaliação do eritrograma de bufalos (Bubalus bubalis) criados na região do Vale do Ribeira em São Paulo. Braz J Vet Res Anim Sc 29: 113-119.

23. Silva MB, D'Angelino JL, Araujo WP, Galhardo M, Garcia M, Birgel EH. 1992. Leucograma de búfalas criadas no Vale do Ribeira, Sao Paulo. Influencia de fatores raciais e etarios. Braz J Vet Res Anim Sc 29: 121-129.

24. Silva RJ, Araújo AA, Lourenço JB, Batista R, Alves NF, Rossetto A. 2011. Perfil hematológico de búfalas da raça Murrah, criadas ao sol e à sombra, em clima tropical da Amazônia Oriental. Acta Amazónica 41: 425-430.
25. Vale EO, Vargas JD, Vale OM, Oviedo MG, Castejón O, García M. 2002. Niveles de inmunoglobulinas (Ig) en suero sanguíneo de búfalos de agua, bajo dos sistemas de amamantamiento diferentes. Revista Cientifica FVC-LUZ 12: 193-201.

26. Vale EO, Camacho JE, Oviedo MG, García M, Vale OR. 2004. Estudio epidemiológico de la casuística patológica en dos rebaños de búfalos de agua (Bubalus bubalis) del municipio Mara, estado Zulia. Venezuela. Revista Cientifica FVC-LUZ 14: 40-53.

27. Vale WG, Ohashi OM. 1994 Problems of reproduction in buffaloes. Buffalo Journal Suppl. 2: 103-122.

28. Van Soest PJ. 1994. Nutritional Ecology of the Ruminant, 2nd ed., Cornell Univ. Press, Ithaca, 476 p.

\section{SJR Journal \& Country Rank}

\section{Powered by SCCPPUS"}

\section{Revista Veterinaria aumentó su índice de impacto}

Noticias de Scimago Research Group (Scimago Journals \& Country Ranks, Scopus-Elsevier) comunican que la publicación de nuestra casa, Revista Veterinaria, aumentó su índice de impacto. El índice SJR mide la influencia científica (impacto) del artículo de una revista, expresando cuán importante es el "artículo promedio" de la publicación en la discusión científica global (sistema Thomson Reuters).

Para nuestra revista, tal indicador había sido de 0,03 entre 2008 y 2011, aumentando a 0,05 en 2012 y a 0,11 en 2013, último período evaluado. El aumento fue del $370 \%$. Asimismo, surge para nuestra publicación un sostenido descenso del indicador que relaciona "citas versus autocitas", demostrando que los autores de los artículos están abandonando la práctica de citar sus propias publicaciones anteriores.

Por último, se advierte que según este portal, nuestra "Revista Veterinaria" continúa siendo la única publicación de esta rama de la ciencia que posee índice de impacto en Argentina. Para el resto del cono sur tal distinción recae en Brasil, Chile, Colombia y Venezuela. No registran índice de impacto las revistas de veterinaria de Bolivia, Paraguay, Uruguay, Perú y Ecuador. En revistas de veterinaria, a nivel mundial el mayor índice de impacto (1,22 puntos) recae en Veterinary Microbiology (Amsterdam, Holanda). 